\title{
Retraction Note to: Anti-Fracture Efficacy of Risedronic Acid in Men
}

\section{A Meta-Analysis of Randomized Controlled Trials}

\section{Zhao-Ming Zhong ${ }^{1} \cdot$ Jian-Ting Chen ${ }^{1}$}

Published online: 28 January 2021

(c) Springer Nature Switzerland AG 2021

\section{Retraction to: Clin Drug Invest (2009) 29(5):349-357 https://doi.org/10.2165/00044011-20092 9050-00007}

The authors have retracted this article because since its publication two $[1,2]$ of the four studies included in the meta-analysis (cited as references 13 and 14 in the article) have been retracted. The results of this meta-analysis are therefore invalid. Both authors agree with this retraction.

\section{References}

1. Sato Y, Honda Y, Iwamoto J. Risedronate and ergocalciferol prevent hip fracture in elderly men with Parkinson disease. Neurology. 2007;68:911-5.

2. Sato Y, Iwamoto J, Kanoko T, et al. Risedronate sodium therapy for prevention of hip fracture in men 65 years or older after stroke. Arch Intern Med. 2005;165:1743-8.

The original article can be found online at https://doi. org/10.2165/00044011-200929050-00007.

Jian-Ting Chen

chenjt99@tom.com

1 Department of Orthopedic and Spinal Surgery, Nanfang Hospital, Southern Medical University,

1838 North Guangzhou Avenue, Guangzhou 510515,

People's Republic of China 